\title{
Photosynthesis and sucrose metabolism in leaves of Arabidopsis thaliana aos, ein4 and rcd1 mutants as affected by wounding
}

\author{
Edyta Lukaszuk $^{1} \cdot$ Magdalena Rys $^{2} \cdot$ Katarzyna Możdżeń $^{3} \cdot$ Iwona Stawoska $^{3} \cdot$ \\ Andrzej Skoczowski ${ }^{3} \cdot$ Iwona Ciereszko $^{1}$
}

Received: 27 October 2016/Revised: 8 November 2016/Accepted: 28 November 2016/Published online: 2 December 2016

(c) The Author(s) 2016. This article is published with open access at Springerlink.com

\begin{abstract}
We have investigated the influence of mechanical wounding of Arabidopsis rosette leaves on photochemical activity of photosystem II, gas exchange, sugar content and sucrose metabolism in wild-type plants and mutants impaired in hormonal balance. The aos (jasmonate deficiency), $r c d l$ (reduced sensitivity to ABA, ethylene, and methyl-jasmonate), and ein4 (ethylene insensitivity) mutants have been used. Generally, mechanical injury led to dynamic changes in metabolism, especially in sugar and carotenoid contents. Whereas all mutants showed lower photosynthesis and respiration in comparison to the wildtype plants, leaf wounding caused a decrease in respiration in aos and ein 4 , and an increase in respiration in wild type. The mechanical injury triggered an increase of the activities of sucrose hydrolysing enzymes, such as sucrose synthase (SuSy) and several types of invertases, which was most evident in case of $r c d l$ and aos plants. This was correlated with injury-related changes in soluble sugars in the mutants, but not in wild-type plants where sugar content was not significantly affected by wounding. The results confirm the key role of stress hormones, such as jasmonate and ethylene, in mediating stress responses after wounding. The outcome
\end{abstract}

Communicated by LA. Kleczkowski.

Iwona Ciereszko

icier@uwb.edu.pl

1 Department of Plant Physiology, Institute of Biology, University of Bialystok, Ciolkowskiego 1J, 15-245 Bialystok, Poland

2 The Franciszek Górski Institute of Plant Physiology, Polish Academy of Science, Niezapominajek 21, 30-239 Krakow, Poland

3 Department of Plant Physiology, Pedagogical University of Cracow, Podchorążych 2, 30-084 Krakow, Poland of the experiments also underlines important roles of SuSy and invertase in regeneration of injured tissues, most probably by providing precursors for cell wall biosynthesis and by modulating sugar-signalling in plant cells.

Keywords Carbohydrates - Chlorophyll $a$ fluorescence . FT-Raman spectroscopy · Invertase · Jasmonate-deficient mutant $\cdot$ Sucrose synthase

$\begin{array}{ll}\text { Abbreviations } \\ \text { Aos } & \text { JA deficient mutant } \\ \text { CIN } & \text { Neutral invertase } \\ \text { cwINV } & \text { Cell wall associated invertase } \\ \text { ein4 } & \text { Ethylene insensitive mutant } \\ \text { Fv/Fm } & \text { Photochemical efficiency of PSII } \\ \text { JA } & \text { Jasmonic acid } \\ \text { NPQ } & \text { Nonphotochemical quenching } \\ \text { qP } & \text { Quenching in steady-state } \\ \text { QY } & \text { Steady-state quantum yield } \\ \text { rcd1-1 } & \text { Radical-induced cell death 1 mutant with } \\ & \text { reduced sensitivity to ABA, ethylene, and methyl } \\ & \text { jasmonate } \\ \text { ROS } & \text { Reactive oxygen species } \\ \text { SuSy } & \text { Sucrose synthase } \\ \text { VIN } & \text { Vacuolar invertase } \\ \text { W 2 } & 2 \text { h after wounding } \\ \text { W 24 } & \text { 24 h after wounding } \\ \text { Wt } & \text { Wild type plants }\end{array}$

\section{Introduction}

Wounding of plant tissues is a common result of an insect/ animal feeding, strong wind, rain, or human agricultural activities. Several studies have shown that various plant 
hormones and signalling molecules are involved in wounding response-jasmonic acid (JA), ethylene, and abscisic acid (ABA) are major plant-specific hormones which constitute natural defense mechanism to protect against wounding (Reymond et al. 2000; León et al. 2001; Maffei et al. 2007; Koo and Howe 2009; Łukaszuk and Ciereszko 2012; Machado et al. 2015). The interaction and balance between hormones and sugars (and sometimes reactive oxygen species, ROS) forms a complex signalling network affecting various aspects of resistance, including local and systemic response. Wounding, as a stress factor, leads to some dynamic changes including the modulation of ion flux, ROS production, induction of MAP kinases. As a result, the induction of genes involved in cellular repair and pathogen-defense occurs, as well as changes in the quality and content of phytochemicals (Reymond et al. 2000; Lafta and Fugate 2011; Savatin et al. 2014; Lulai et al. 2016). All these responses, and the time of their emergence, may differ depending on plant species or plant organs. The great tool to study these responses are plant mutants, including the Arabidopsis thaliana hormonal mutants which are commonly used genetic tools (Meyerowitz 2001; Ahlfors et al. 2004; Ciereszko and Kleczkowski 2006; Koo and Howe 2009; Ljung et al. 2015). Several mutants defective in jasmonate biosynthesis and signalling have been isolated and used in the case of recent studies which have analyzed plant responses to insects or pathogen attack (Berger 2002; Machado et al. 2015)

Sugars are involved in plant development, metabolism, and responses to various stress conditions, e.g., phosphate deficit, water stress, anoxia (Ciereszko and Kleczkowski 2005; Couée et al. 2006; Polit and Ciereszko 2012; Tauzin and Giardina 2014). Sucrose as an end product of photosynthesis is the major translocated form of carbon in plants. Sucrose is metabolized by invertases (EC 3.2.1.26) and sucrose synthase (SuSy, EC 2.4.1.13) into hexoses (Rosa et al. 2009). These processes are important for the wounded/infected plants, because carbon skeletons are required in the damaged area for the synthesis of new molecules and as an energy source in biosynthetic reactions (Quilliam et al. 2006; Lafta and Fugate 2011; Tauzin and Giardina 2014). Additionally, sugars as signal molecules may regulate gene expression and a variety of metabolic processes through hexokinase-dependent and independent pathways (Couée et al. 2006; Lastdrager et al. 2014; Kunz et al. 2014, 2015). Several reports have indicated that stress conditions affect sugar metabolism, e.g., cadmium stress led to decrease in invertases and SuSy activity in pea (Devi et al. 2007). Wounding has been evidenced to reduce sucrose content in sugar beet and sugar cane (Rosenkranz et al. 2001; Chandra et al. 2012), while phosphate deficiency increased glucose and starch content in bean or $A$. thaliana leaves (Ciereszko and Barbachowska 2000; Ciereszko and Kleczkowski 2005). On the other hand, cold stress has resulted in accumulation of glucose, fructose, sucrose and starch (Strand et al. 1997). It has been established that mechanical wounding induces expression and the activity of cell wall and vacuolar invertases in the sugar beet tap-root (Rosenkranz et al. 2001). Photosynthesis and respiration intensities are often affected by stress, as well (Quilliam et al. 2006; Lafta and Fugate 2011). Chlorophyll $a$ fluorescence during photosynthesis is low; however, disturbances in this process provoked by stress usually intensify the fluorescence emission (Baker and Rosenqvist 2004). Moreover, co-regulation of photosynthesis and carbohydrate metabolism may influence enzyme activity and whole plant metabolism (Berger et al. 2007).

Sugars can activate specific hormone-crosstalk transduction pathways, resulting in modifications of various gene expression and enzyme activity (León and Sheen 2003; Lastdrager et al. 2014; Ljung et al. 2015). Sugar production, transport, and metabolism are modified by hormones. Thus, crosstalk between hormones and sugar occurs through the regulation of hormone synthesis (e.g., ABA and gibberellins) by sugar, while hormones (e.g., ABA, cytokinins) modify sugar metabolism (León and Sheen 2003; Ljung et al. 2015). It has been found that glucose stimulates ABA synthesis and limits the sensitivity to ethylene (León and Sheen 2003). On the other hand, jasmonate-dependent depletion of soluble sugars has been observed (Machado et al. 2015). What is more, the role of jasmonates in the regulation of plant primary metabolism is also unclear. The plant responses to wounding resulting in modification of sugar content and metabolism are still poorly understood.

The goal of the present study was to contribute to better understanding of the effect of mechanical wounding on sucrose metabolism and photosynthesis. Additionally, we wanted to test whether a deficit, or insensitivity, to the stress hormones had an influence on sugar metabolism, and plants responses to wounding thus the A. thaliana mutants: aos, ein4, and rcdl were used, in which carbohydrate metabolism has not been studied. Photochemical efficiency of PSII and gas exchange estimations allowed us to gain an insight into the condition of photosynthetic apparatus and the ability of mutants, the ones with low sensitivity to crucial plant hormones, to respond to wounding stress.

\section{Materials and methods}

\section{Plant material}

Seeds of Arabidopsis thaliana (L.) Heynh. ecotype Columbia wild-type plants (wt) and hormonal mutants 
(ein4-ethylene insensitive, $r c d 1-1$-reduced sensitivity to ABA, ethylene, and methyl jasmonate, aos-JA-deficient) were obtained from the European Arabidopsis Stock Centre (NASC). Mutants were described by Roman et al. (1995), Overmyer et al. (2000), Park et al. (2002) and Ahlfors et al. (2004). Seeds were stratified in the dark for $72 \mathrm{~h}$ at $4{ }^{\circ} \mathrm{C}$, then soil-grown for 6 weeks in a growth chamber with a photoperiod of $10 \mathrm{~h} \quad$ light $/ 4 \mathrm{~h}$ dark, PAR $100 \mu \mathrm{mol} \mathrm{m} \mathrm{s}^{-1}, 23{ }^{\circ} \mathrm{C} / 20{ }^{\circ} \mathrm{C}$ temperature and $65 \%$ humidity. After 6 weeks, half of the leaf (with bundle sheath) was cut with scissors, wounding was repeated in half of all leaves in the rosette (Fig. 1). All experiments were performed 2 and $24 \mathrm{~h}$ after wounding with intact plants as controls. Leaves from wild-type plants and mutants were harvested to measurements after $4-5 \mathrm{~h}$ of light period. Despite the injury of leaves, plants were able to grow and flower (especially wt). All experiments were carried out in 3-5 replicates and 3-5 independent series of experiments.

\section{Fourier transform Raman spectroscopy measurements}

FT-Raman spectroscopy is now a common technique for the qualitative identification of metabolites, applied to carotenoids, sugars, lipids, flavonoids or polyphenols measurements in plants (Baranska et al. 2013; Skoczowski and Troć 2013). FT-Raman spectra were recorded with a Nicolet NXR 9650 spectrometer fitted with a liquid nitrogen-cooled germanium detector. The leaf of
A. thaliana was illuminated with a Nd:YAG laser, emitting at $1064 \mathrm{~nm}$. All spectra were recorded in the range from 100 to $4000 \mathrm{~cm}^{-1}$ with a spectral resolution of $4 \mathrm{~cm}^{-1}$, average of 64 scans, using Omnic/Thermo Scientific Software. Ten spectra were collected for each control and wounded plant, then spectra were classified according to the main biochemical components using hierarchical cluster analysis. The Ward's algorithm was used to obtain dendrograms to compare the chemical composition. The analysis was performed based on the normalized FT-Raman spectra of A. thaliana genotypes in the range of $700-1800 \mathrm{~cm}^{-1}$ by STATISTICA software (StatSoft, Inc. 2011).

\section{Measurement of chlorophylls and carotenoids content}

Pigments (chlorophyll a, b, and carotenoids) from the rosette leaves (control and injured) of wild-type and mutants were extracted with $80 \%$ acetone and measured spectrophotometrically according to Wellburn (1994).

\section{Chlorophyll a fluorescence measurements}

Chlorophyll fluorescence images were captured with a FluorCAM imaging system (PSI, Brno, Czech Republic) and analyzed with FluorCam6 software package (ver. 1.8, Photon System Instruments). Chlorophyll fluorescence was measured in the same plant: before wounding, and 2 and $24 \mathrm{~h}$ after wounding. Plants were dark-adapted for $20 \mathrm{~min}$

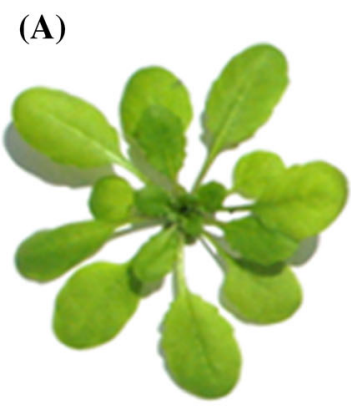

wt

(B)

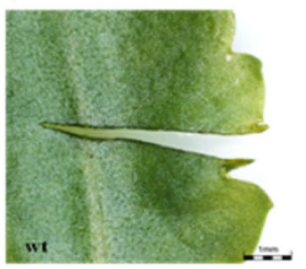

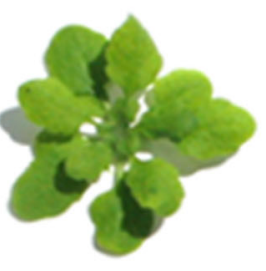

redil

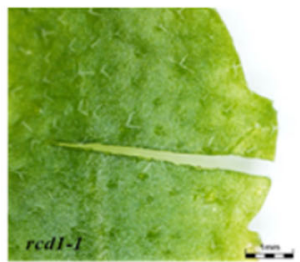

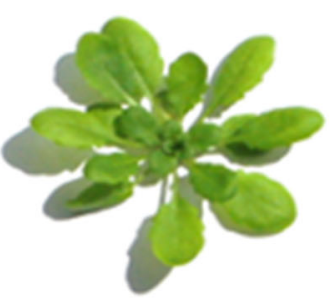

acs

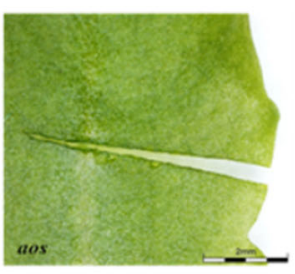

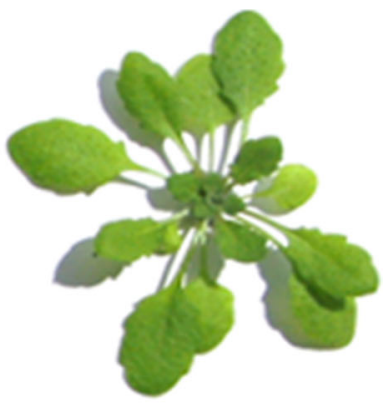

$\operatorname{ein} 4$

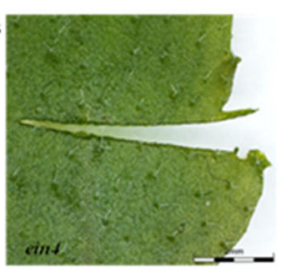

Fig. 1 Arabidopsis thaliana wild-type (wt) and mutants $r c d 1$, aos, ein4 rosettes morphology after 6 week growth (a), wounding treatment of rosette leaves (b) 
and the dark level fluorescence yield $\left(F_{0}\right)$ was recorded at a very low light intensity (less than $1 \mu \mathrm{mol}$ photon $\mathrm{m}^{-2} \mathrm{~s}^{-1}$ ). The maximum fluorescence yield (Fm) was measured at the saturating flash of about $2500 \mu \mathrm{mol}$ photons $\mathrm{m}^{-2} \mathrm{~s}^{-1}$ for $1 \mathrm{~s}$ to reduce plastoquinone pool. Afterwards, the plants were light-adapted under red-orange actinic light (180 $\mu \mathrm{mol}$ photon $\mathrm{m}^{-2} \mathrm{~s}^{-1}$ ). The following chlorophyll fluorescence coefficients: photochemical quenching (qP), non-photochemical quenching in light (NPQ) and PSII quantum yield in light (QY) were measured at steady-state photosynthesis according to the procedure described by Gabara et al. (2012).

\section{Photosynthesis and respiration measurements}

The rate of net photosynthetic $\mathrm{O}_{2}$ evolution and respiration in the leaves of wild-type and mutants was measured using a Clark-type oxygen electrode (Hansatech Instruments Ltd., England) under the photon flux density of $500 \mu \mathrm{mol} \mathrm{m} \mathrm{m}^{-2} \mathrm{~s}^{-1}$ at $25{ }^{\circ} \mathrm{C}$, as described by Akhkha et al. (2001). $\mathrm{CO}_{2}$ in the reaction chamber (LD1/2, Hansatech, King's Linn, Great Britain) was generated by $15 \mathrm{mM}$ sodium bicarbonate; Hansatech LS2 lamp served as a light source.

\section{Soluble sugars content determinations}

Plant material was collected 2 and $24 \mathrm{~h}$ after wounding (same for the control plants) and frozen in liquid nitrogen. Sugars were extracted with $80 \%$ ethanol; ethanol extracts were concentrated by evaporation under vacuum. Glucose and sucrose content was quantified enzymatically using glucose oxidase and peroxidase as described by Ciereszko and Barbachowska (2000). Soluble (reducing) sugars content was estimated with the arsenomolybdate reagent according to the method of Somogyi-Nelson (Nelson 1944) and the absorbance was measured at $540 \mathrm{~nm}$.

\section{Sucrose hydrolysing enzymes extraction and activity}

Cell wall invertase (cwINV) and vacuolar invertase (VIN) were extracted from plant tissues with $100 \mathrm{mM} \mathrm{Na}$ acetate buffer ( $\mathrm{pH} 4.5$ ) and activity was measured as described by Ciereszko and Barbachowska (2000). Soluble invertases were analyzed in the supernatants, whereas the insoluble form was measured in the pellet. To determine invertases activity, the reaction mixtures were measured after 10-20 min incubation at $37^{\circ} \mathrm{C}$ of the enzymatic extract with $100 \mathrm{mM} \mathrm{Na}$ acetate buffer (pH 4.5) and $100 \mathrm{mM}$ sucrose.
Neutral invertase (CIN) and SuSy were extracted in reaction buffer $(50 \mathrm{mM}$ MOPS-NaOH $\mathrm{pH} 7.0,5 \mathrm{mM}$ $\mathrm{MgCl}_{2}, 1 \mathrm{mM}$ EDTA, $2.5 \mathrm{mM}$ DTT, $0.05 \%$ Triton $\mathrm{X}, 2 \%$ PVP), as described by Ciereszko and Barbachowska (2000). The activity of CIN was detected after $30 \mathrm{~min}$ incubation at $37^{\circ} \mathrm{C}$ in a reaction mixture containing $50 \mathrm{mM}$ MOPS-NaOH, pH 7.0, $100 \mathrm{mM}$ sucrose, water and the extract. The sugars produced in the reaction were determined as above.

To determine SuSy activity, reaction mixtures containing $50 \mathrm{mM}$ MOPS-NaOH (pH 7.5), $5 \mathrm{mM} \mathrm{MgCl}_{2}, 10 \mathrm{mM}$ UDPG, $50 \mathrm{mM}$ fructose and the extract were incubated at $37{ }^{\circ} \mathrm{C}$ for $20 \mathrm{~min}$ then terminated with $0.5 \mathrm{~mL} 1 \mathrm{~N} \mathrm{NaOH}$ and placed in boiling water. Subsequently $0.1 \%(\mathrm{v} / \mathrm{v})$ resorcinol in $95 \%$ ethanol and $30 \%$ HCL were added, and the tubes were incubated at $80{ }^{\circ} \mathrm{C}$ for $10 \mathrm{~min}$. The tubes were allowed to cool down and the absorbance was measured at $540 \mathrm{~nm}$.

\section{Measurement of soluble proteins content}

The soluble proteins content was determined by the procedure of Bradford (1976). The absorbance at $595 \mathrm{~nm}$ was measured in enzymatic extract after 15 min incubation at room temperature with the Bradford reagent (Sigma) and compared to a standard BSA curve.

\section{Statistical analysis}

Data were analyzed statistically using analysis of variance and tested for significant differences $(p \leq 0.05)$ using oneway ANOVA, Duncan test of STATISTICA software (StatSoft, Inc. 2011).

\section{Results}

Mechanical wounding of $A$. thaliana rosette leaves of wildtype and mutants did not significantly affect the growth parameters and morphology of plants (Table 1; Fig. 1). Hormonal imbalance generally affected the morphology of intact plant leaves-the $r c d l$ mutant was smaller compared to wild-type, with a lower fresh weight, shorter rosette diameter and leaves with large amount of trichomes, aos was more similar to control plants, but the rosette diameter of ein4 was larger than wild type (Fig. 1). Chlorophyll and carotenoids concentrations in general were not affected after wounding, except aos and ein4, where chlorophyll and carotenoids content increased (Table 1). Wounding of rosette leaves did not have a significant effect on the soluble proteins content (Table 1). 


\section{Changes in the chemical composition of mutants leaves after injury (FT-Raman spectra)}

Raman spectroscopy is a rapid technique that does not need any earlier sample preparation; each sample is irradiated by monochromatic light deriving from a laser source (Schulz et al. 2005; Skoczowski and Troć 2013). It allows for determination of chemical composition of various tissues on the basis of changes in the vibrational modes of molecules; moreover, computer system (Fourier transform, FT) allows fast and sensitive measuring of weak signals (Baranska et al. 2013).

In the analyzed A. thaliana wild-type plants, as well as in mutants, three bands have been identified for carotenoids (Fig. 2). The most intensive bands at 1526 and $1158 \mathrm{~cm}^{-1}$ could be assigned to $\mathrm{C}=\mathrm{C}$ and $\mathrm{C}-\mathrm{C}$ stretching vibration of the polyene chain, whereas the band at $1002 \mathrm{~cm}^{-1}$ was related to rocking modes of methyl groups attached to the $\mathrm{C}-\mathrm{C}$ bonds of the main chain (Schulz et al. 2005; Withnall et al. 2003). The main carotenoid pigments presented in the leaves are 9-conjugated $\mathrm{C}=\mathrm{C}$ carotenoid compounds, such as $\beta$-carotene (also $\alpha$-carotene, usually in a much lower concentration), lutein, zeaxanthin or antheraxanthin, similar to the results obtained by Schulz et al. (2005). In addition to carotenoid signals, other bands mainly in the $800-1500 \mathrm{~cm}^{-1}$ regions were detected (Fig. 2). These bands could be attributed mostly to monosaccharides, disaccharides and polysaccharides and for this reason the region is called the fingerprint of carbohydrates. Bands at $854 \mathrm{~cm}^{-1}$ could be assigned to $\mathrm{C}-\mathrm{O}-\mathrm{C}$ skeletal modes of sugars (mainly glucose and sucrose). Bands at $866 \mathrm{~cm}^{-1}$ were related to the vibration of $\mathrm{C}-\mathrm{H}$, while the peaks at $915 \mathrm{~cm}^{-1}$ were associated with both $\mathrm{C}-\mathrm{H}$ and $\mathrm{COH}$ vibrations. The peaks around $1260-1280 \mathrm{~cm}^{-1}$ represented the $\mathrm{C}-\mathrm{OH}$ vibration modes, whereas the peaks at $1443 \mathrm{~cm}^{-1}$ could be interpreted as the $\mathrm{C}-\mathrm{OH}$ stretching vibrations. The peaks at $1070-1080 \mathrm{~cm}^{-1}$ could be correlated with $\mathrm{C}-\mathrm{H}$ and $\mathrm{COH}$ vibrations in carbohydrates (Fig. 2).

The cluster analysis (Fig. 3) carried out in the $700-1800 \mathrm{~cm}^{-1}$ region based on the FT-Raman spectra (Fig. 2) showed the differences in the content of metabolites (mainly sugars and carotenoids) in the leaves of $A$. thaliana after wounding. The most visible changes in the chemical composition of the leaves were observed $24 \mathrm{~h}$ after wounding for wild-type and $r c d l$ (Fig. 3b). Metabolic changes in the aos mutant were very similar both at 2 and $24 \mathrm{~h}$ after damage as compared to control (Fig. 3c). Metabolic changes in response to stress in the ein 4 mutant were rapid (within $2 \mathrm{~h}$ ) but short-termed, as no significant spectroscopic changes in the tested region were detected after $24 \mathrm{~h}$ (Fig. 3d). 

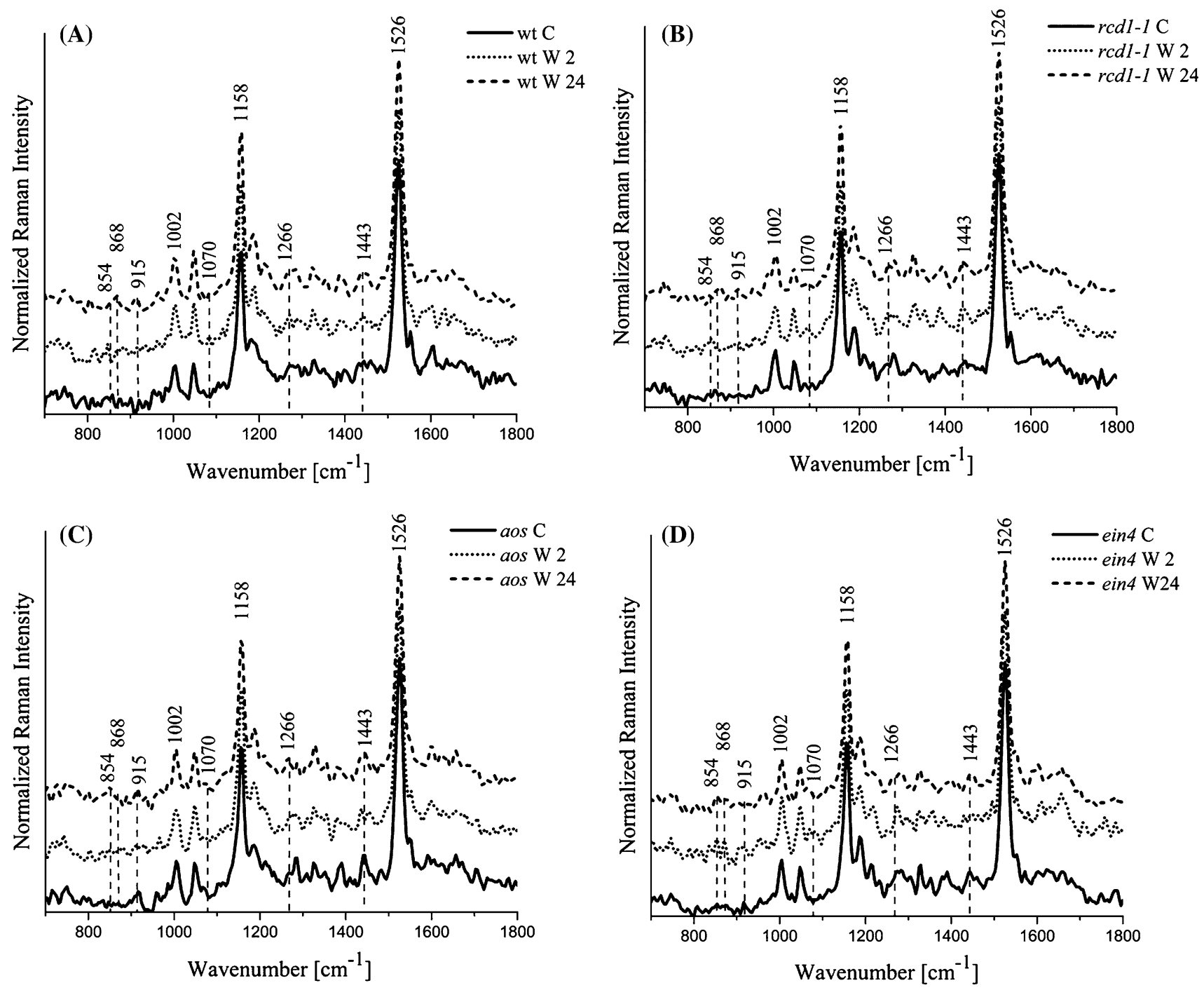

Fig. 2 FT-Raman spectra of Arabidopsis thaliana leaves: a wt, $\mathbf{b} r c d l$, $\mathbf{c}$ aos, and $\mathbf{d}$ eint mutants. Spectra were recorded for the control leaves (c), after wounding $2 \mathrm{~h}$ (W 2) and $24 \mathrm{~h}$ (W 24)

\section{Photosynthesis and respiration after wounding of rosette leaves}

The influence of wounding on PSII condition has been investigated by chlorophyll $a$ fluorescence. Chlorophyll a fluorescence is a non-invasive tool to examine changes in photosynthetic apparatus. The reduction of maximum efficiency of PSII $(\mathrm{Fv} / \mathrm{Fm})$ was observed $2 \mathrm{~h}$ after wounding in aos and ein4, whereas the reduction of this parameter in $r c d l$ was not significant (Fig. 4a). Other fluorescence quenching coefficients indicated that among all tested plants the $r c d l$ mutant differed the most (Fig. 4). The decrease in non-photochemical quenching (NPQ) parameter and photochemical quenching coefficient in steady-state (qP) was observed in $r c d l$ both 2 and $24 \mathrm{~h}$ after wounding (Fig. 4b, c). Therefore, the reduction of $\mathrm{qP}$ in aos has also been recorded (Fig. 4c), due to decrease in open PSII reaction centers after stress treatment. The reduction in steady-state PSII quantum yield (QY) in $r c d l$ has been detected (Fig. 4d). Chlorophyll fluorescence parameters in the ein 4 mutant appeared similar to the wild type (Fig. 4a-d).

Within a short time after the injury $(2 \mathrm{~h})$, photosynthetic oxygen evolution decreased in wild-type leaves (Fig. 5a). However, $24 \mathrm{~h}$ after wounding, the photosynthesis increased to the control level. Among tested stress conditions mechanical wounding did not affect significantly the photosynthetic oxygen evolution in A. thaliana mutants. Surprisingly, all of the tested mutants had lower photosynthetic activity than the wild-type plants (Fig. 5a).

Respiration rate in the wild-type plants decreased $2 \mathrm{~h}$ after wounding. On the other hand, $24 \mathrm{~h}$ after injury respiration rate increased and was approximately twice as 
Fig. 3 Dendrograms of a cluster analysis of the FTRaman spectra of Arabidopsis thaliana leaves for the control leaves (c), after $2 \mathrm{~h}$ (W 2) and $24 \mathrm{~h}$ (W 24) after wounding. a wt, b $r c d 1$, c aos, and d ein 4 mutants. Cluster analysis was performed on the basis on normalized FT-Raman spectra at the range of $700-1800 \mathrm{~cm}^{-1}$ with the use of Ward's algorithm
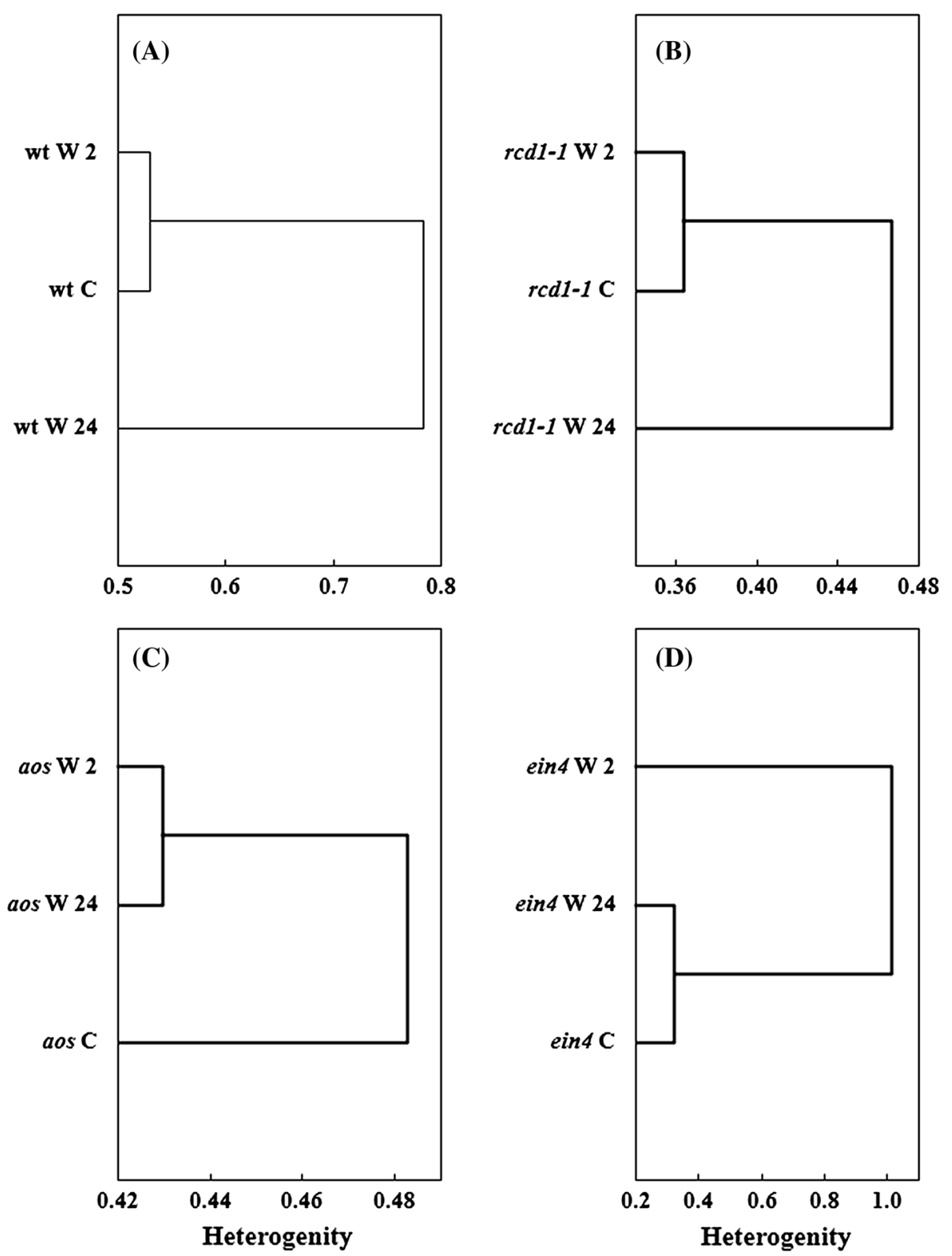

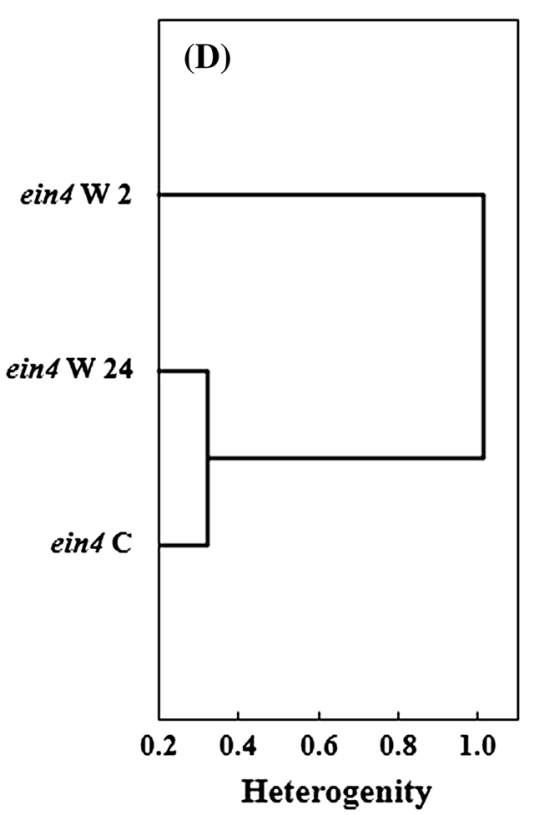

high as compared to control (Fig. 5b). Mutants generally had lower respiration rate compared to wild type. Enhanced respiration was observed two hours after injury in $r d c 1$. Mutants insensitive to ethylene (ein4) and with deficiency of JA (aos) indicated the highest reduction in the respiration rate-24 $\mathrm{h}$ after wounding stress (Fig. 5b).

\section{Sugar content after leaf injury}

Soluble sugars content in mutants generally increased after $24 \mathrm{~h}$ of wounding stress (Fig. 6a), while in rcdl some accumulation was observed after $2 \mathrm{~h}$. However, sugar content was not affected by injury in wild type. Glucose content increased significantly in ein $4,2 \mathrm{~h}$ and $24 \mathrm{~h}$ after injury of rosette leaves (Fig. 6b), whereas rcdl mutants had higher glucose content compared to wild type. The analyses of sucrose content revealed that $r c d l$ had lower content of this sugar compared to other plants. What is more, leaf wounding increased sucrose content only in this mutant (Fig. 6c). However, starch content was lower in rcdl than in wild-type leaves (data not shown) indicating different distribution of assimilated carbon.

\section{Sugar hydrolysing enzyme activities after wounding}

Wounding affected invertases activity both in wild-type plants and mutants (Fig. 7a-c). The activity of vacuolar invertase increased $2 \mathrm{~h}$ and $24 \mathrm{~h}$ after wounding the rosette leaves in aos and rcdl (Fig. 7a). The activity of cell wall invertase was also elevated after injury in those mutants 
Fig. 4 Chlorophyll

fluorescence parameters of the 6 -week-old rosette leaves in wild-type (wt), $r c d 1$, aos and ein4 Arabidopsis thaliana mutants at $2 \mathrm{~h}$ (W 2) and $24 \mathrm{~h}$ (W 24) after wounding, and in not wounded leaves (c). a Fv/ Fm, b NPQ, $\mathbf{c}$ qP and $\mathbf{d}$ QY. Values of parameters are shown along with SD. The results labelled by asterisks are significantly different $(p \leq 0.05)$
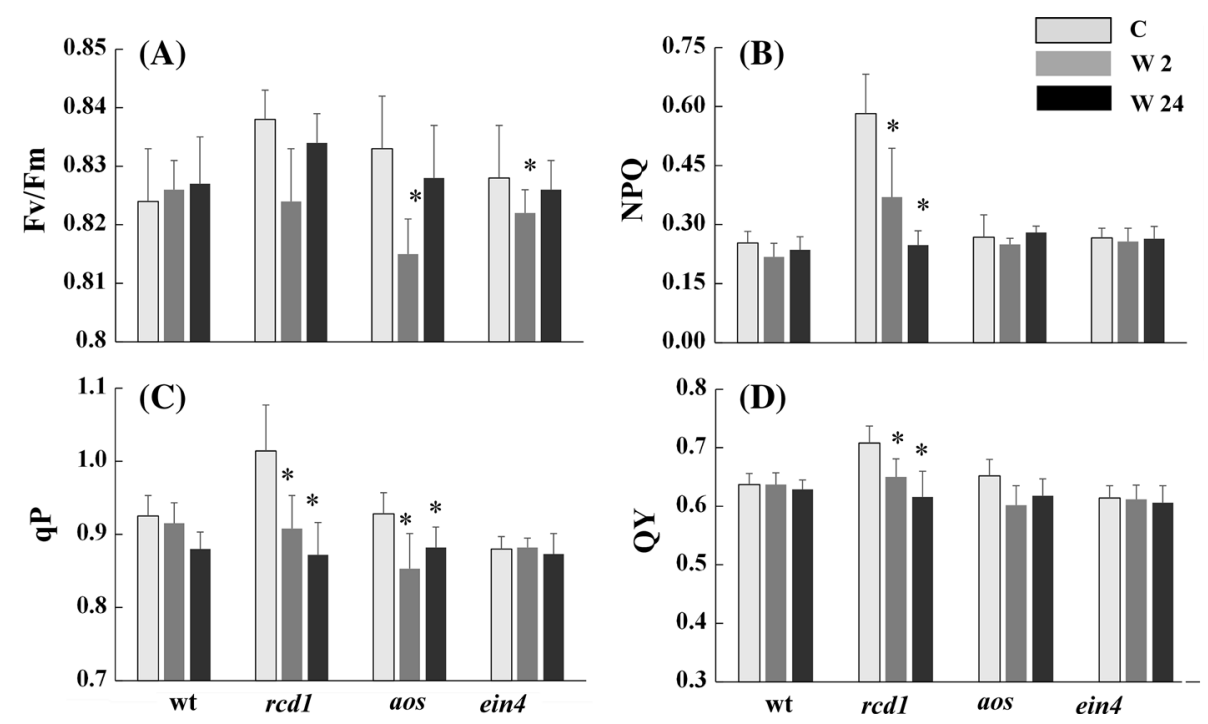

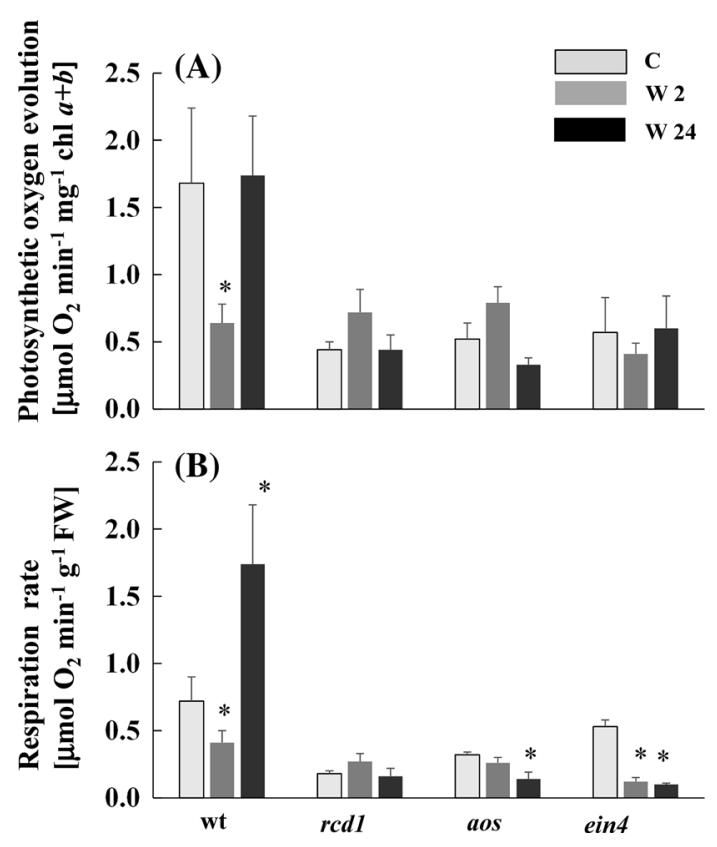

Fig. 5 Photosynthesis and respiration rate in rosette leaves of in wild-type (wt) and rcdl, aos, ein4 Arabidopsis thaliana mutants at $2 \mathrm{~h}$ (W 2) and $24 \mathrm{~h}$ (W 24) after wounding and in control, not wounded leaves (c). a photosynthetic oxygen evolution at photosynthetic active radiation $550 \mu \mathrm{mol} \mathrm{m} \mathrm{m}^{-2} \mathrm{~s}^{-1} ; \mathbf{b}$ respiration rate. Mean values along with SD. The results labelled by asterisks are significantly different $(p \leq 0.05)$

and in the wild-type plants (Fig. 7b). In contrast, wounding stress did not affect VIN and cwINV activity in ein4. The most significant changes in enzyme activity after wounding were recorded for neutral invertase, both in wild-type and mutants, especially in $r c d l$ and aos (Fig. 7c). Wounding enhanced the activity of other cytosolic enzyme, SuSy,
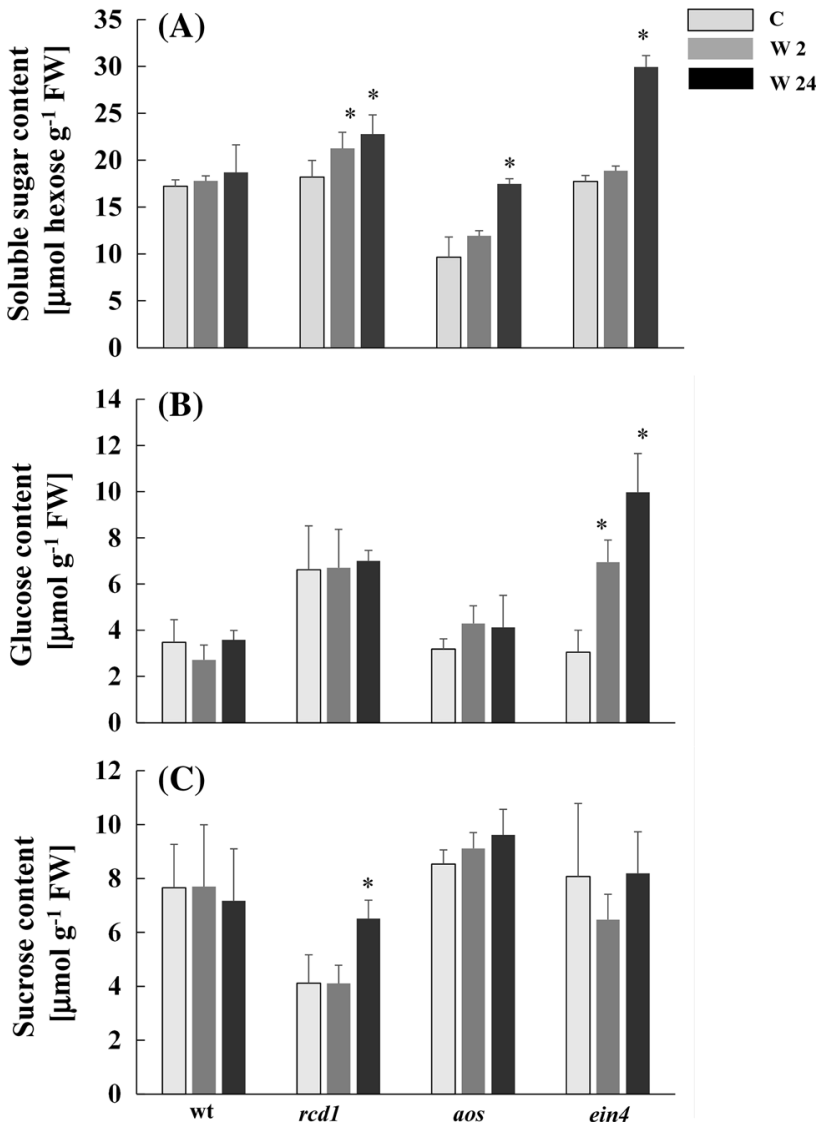

Fig. 6 Carbohydrate content after wounding of the rosette leaves of 6-week-old Arabidopsis thaliana plants at 2 h (W 2) and $24 \mathrm{~h} \mathrm{(W} \mathrm{24)}$ after stress, and in unwounded leaves (c). Leaves from wild-type (wt) plants, $r c d 1$, aos and ein 4 mutants were harvested in the middle of photoperiod (after 4-5 h of light period). Contents of soluble sugars (a), glucose (b) and sucrose (c) are indicated, along with SD. The results labelled by asterisks are significantly different $(p \leq 0.05)$ 
Fig. 7 Activity of enzymes connected with sucrose metabolism after wounding of 6-week-old rosette leaves of Arabidopsis thaliana plants, wild-type (wt) plants, $r c d 1$, aos and ein4 mutants, at $2 \mathrm{~h}$ (W 2) and $24 \mathrm{~h}$ (W 24) after wounding, and in control, unwounded leaves (c). Activity of invertases: vacuolar (a), cellwall associated (b), neutral (c) and sucrose synthase (d) are indicated, along with SD. The results labelled by asterisks are significantly different $(p \leq 0.05)$
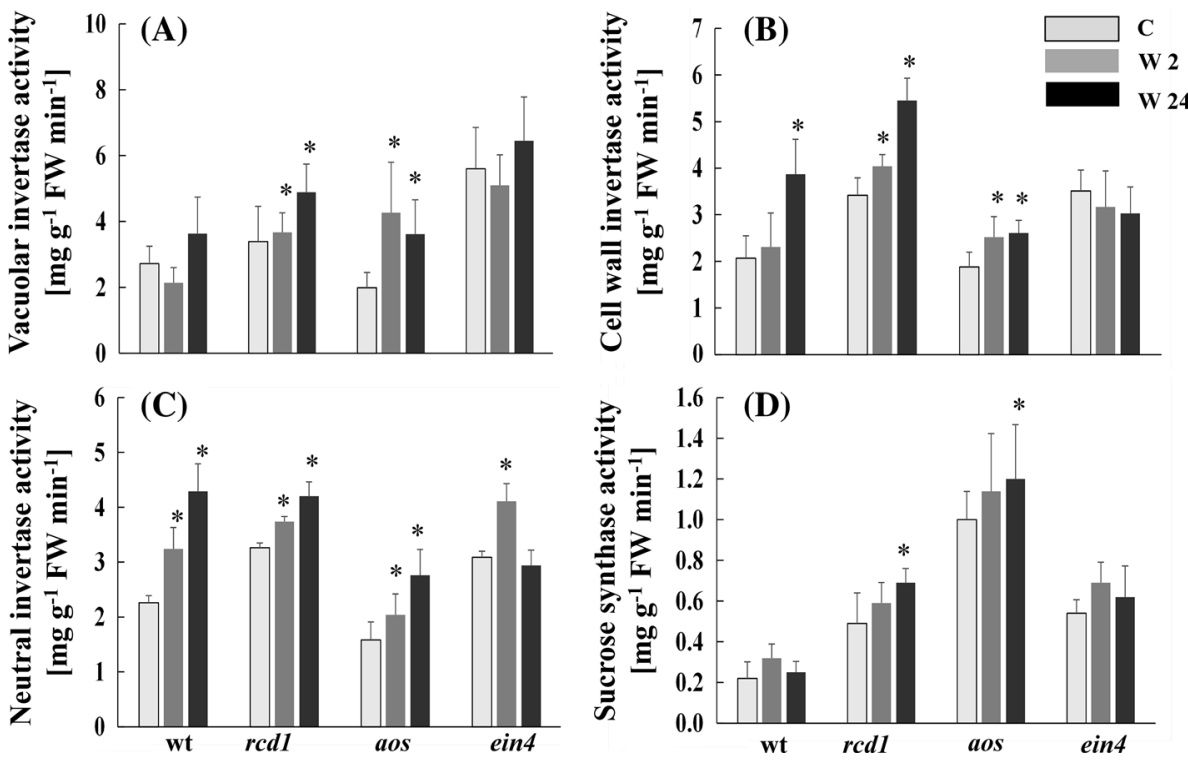

$24 \mathrm{~h}$ after injury of rosette leaves in the $\mathrm{rcdl}$ and aos mutants (Fig. 7d); in contrast, the lowest activity of SuSy were detected in wild type. The highest enzyme activity was found in JA-deficient mutant, aos, about fivefold higher than in wild-type, especially $24 \mathrm{~h}$ after wounding (Fig. 7d).

\section{Discussion}

In this study, the relationship between the wounding stress and hormonal imbalance/sensitivity has been determined. In carried out experiments we have analyzed photosynthesis, respiration, carbohydrate content and activity of key enzymes of sucrose metabolism in A. thaliana aos, $r c d l$, and ein 4 mutants. It has been observed that in leaves of mutants chemical composition, as well as sugar production and metabolism were generally different than in wild-type plants (Figs. 2, 3, 6, 7).

Chlorophyll a fluorescence measurement, as a non-invasive technique, is commonly used to monitor the effects of environmental stress on PSII photochemical activity in vivo (Baker and Rosenqvist 2004; Ritchie 2006). In our experiments, we found that wounding of rosette leaves in wild-type did not affect fluorescence parameters. On the contrary, in $r c d l$ mutant the values of fluorescence parameters were reduced as a result of wounding (Fig. 4), which could be a result of different leaves morphology of $r c d l$ mutant. Maximum quantum efficiency of PSII (Fv/ Fm) decreased $2 \mathrm{~h}$ after wounding in aos and ein4 (Fig. 4a). Wounding of rosette leaves in $r c d l$ caused a decrease of NPQ, qP and QY, however, Fv/Fm change only slightly (Fig. 4). In general, our observations have shown that the injury of wild-type plants did not affect PSII significantly. On the other hand, Chang et al. (2004) showed that wounding of $A$. thaliana leaves caused a decrease of QY after $0.5 \mathrm{~h}$ and an increase of QY $6 \mathrm{~h}$ after stress treatment; however, the injury was much more severe and studied in different growth conditions than in our research. Partial exposure to excess light caused a reduction in Fv/Fm and NPQ in transgenic A. thaliana (Szechyńska-Hebda et al. 2010). Kim and Portis (2005) indicated that heat stress was the cause of reduction of QY (the proportion of absorbed energy used in photochemistry) and net photosynthesis. A decrease in the proportion of absorbed light (used for photosynthetic electron transport through PSII) in the near area from the wound margin in $A$. thaliana leaves were detected already one hour after injury (Quilliam et al. 2006). In our experiments, a reduction of the qP parameter after leaf wounding in the $r c d l$ and aos mutants has been observed (Fig. 4c), this result indicates that reaction centers in PSII are closing. In contrast, other stress condition, heat, caused an increase of $\mathrm{qP}$ in $A$. thaliana leaves (Kim and Portis 2005).

Our results indicate that hormonal imbalance in mutants, or lower sensitivity, has affected photosynthesis and respiration metabolism in plants: $r c d l$, aos and ein 4 mutants had lower activity of these processes than wild type plants. Gas exchange depends on various factors, e.g., on leaf morphology/anatomy or sensitivity to light conditions, which could be different in mutants than wild type. Wounding caused a decrease of photosynthesis and respiration rate $2 \mathrm{~h}$ after leaves injury, mainly in wild-type plants (but also in ein4) (Fig. 5). Microarray data indicate that several photosynthetic genes are repressed by wounding in A. thaliana, probably via ethylene/ethyleneresponsive pathways (Delessert et al. 2004). Respiration significantly increased $24 \mathrm{~h}$ after wounding stress in wild- 
type or after $2 \mathrm{~h}$ in $r c d l$; in contrast, a reduction of respiration rate was observed in all mutants $24 \mathrm{~h}$ after leaves wounding (Fig. 5b). Several other studies regarding the impact of wounding on plant metabolism have indicated that plant injury increases respiration rate and induces demand for respiration substrates-energy is necessary to drive biosynthetic reactions during the repair processes (Quilliam et al. 2006; Lafta and Fugate 2011). It was suggested that in wounded sugar beet roots the activities of early glycolytic enzymes like fructokinase, phosphofructokinase, phosphoglucose isomerase or phosphoglucomutase were limiting for carbon flow through glycolysis (Lafta and Fugate 2011). However, also activity of some sucrose-metabolizing enzymes could funnel carbon skeletons into synthesis of new molecules, after tissue damage, independently of oxygen respiration.

In our study, wounding stress caused stimulation of enzymes associated with sucrose metabolism, particularly invertases. Invertase activity was only partially correlated with changes in sugar content in damage tissues in our experimental conditions (Figs. 6, 7), thus other carbohydrate metabolism-associated enzymes should be checked in the further studies. The activity of acid invertases was reported to be inversely correlated with sucrose content (Rosa et al. 2009; Verma et al. 2011). VIN activity positively correlated with the accumulation of hexoses in sugar storage sinks, such as potato tubers or during fruit ripening in tomato or grape berry (Ruan et al. 2010). In our experiment, in wild-type leaves, we did not observe that higher cwINV or CIN activities result in higher sugar content. We found that the wound stress-stimulated CIN, VIN and cwINV activities resulted in a slightly higher soluble sugars concentration in aos and $r c d l$ (Figs. 6, 7). The activity of invertases was substantially higher than that of SuSy both in damaged and intact leaves. Although SuSy activity in the aos plants was fivefold higher than in wildtype, the glucose and sucrose content in aos was almost at the same level as in wild type (Figs. 6, 7). Product of SuSy activity, UDP-glucose, can be utilized for synthesis of new cell wall polysaccharides or used to support other woundhealing processes, independently of respiratory metabolism. Our preliminary study with aniline blue for staining of callose indicated deposition of callose already $2 \mathrm{~h}$ after stress treatment and fast repairing of injured leaves (data not shown). The most significant changes after wounding were recorded in the JA-deficient mutant, aos, and in rcdl-mutant with modulated abscisic acid, ethylene, and methyl jasmonate responses to stress (Ahlfors et al. 2004). It was observed that invertases activity (cytosolic, vacuolar and cell wall-connected) increased after stress treatment. The analyses of biochemical data and FT-Raman cluster analysis confirmed that after wounding the reaction of $r c d l$ and aos mutants differed the most compared to wild type
(Fig. 2c). The measurements of various hormone contents, and reactive oxygen species, in leaves of those mutants in further studies could be helpful to elucidate the observed results. The recent studies by Machado et al. (2015) indicated that jasmonates might be an important regulator of leaf carbohydrate accumulation (in Nicotiana plants); diurnal, jasmonate-dependent inhibition of invertase activity as possible control mechanism was suggested. In our study aos mutant of Arabidopsis exhibited generally lower activity of invertases (thus higher sucrose content) and higher SuSy activity than other mutants. However, our study indicates that complexity of interactions of hormonal imbalance (in mutants) and enzymes involved in sugar metabolism during wounding stress requires further investigation.

In conclusion, our results demonstrate that the modification of stress hormones content/sensitivity in $r c d l$, aos and ein4 mutants of A. thaliana affects sugar production/ metabolism in plants. So far, carbohydrate metabolism has not been studied in those mutants, and to our knowledge, the role of jasmonates in the regulation of sugar metabolism was also unknown. Mutants reactions related to basic metabolic processes-photosynthesis and respiration-differed significantly from those observed in wild-type plants. In the study described, wound responses of the mutants with reduced sensitivity to MeJA, ABA and ethylene ( $r c d l$, Ahlfors et al. 2004), and JA-deficient (aos) were usually different than those of the wild-type plants. The activity of cytosolic enzymes (CIN, SuSy) involved in sucrose metabolism was also high in the $r c d l$ and aos mutants; the high activity of sugar metabolism enzymes after injury of leaves only partially correlated with measured sugars content. Therefore, we conclude that sugars are likely to be involved in stress signalling in response to injury. Given that the signalling action of distinct sugars may occur via different signal transduction pathways (Kunz et al. 2014), the roles of SuSy and invertases (which regulate the relative contents of sucrose, glucose and fructose) appear particularly important in wounding stress responses.

Author contribution statement IC and EL wrote the manuscript, EL determined the gas exchange, enzymes activity, protein and sugar content. EL and KM measured chlorophyll fluorescence. MR, IS and AS carried out the FT-Raman spectrometric studies. IC and AS supervised the work, gave final corrections and critical revision.

Acknowledgement We thank S. Maksymiuk and K. Heronimek for help with measurements of chlorophyll and carotenoids content, and acid invertases activity. The work was supported by grant BMN-154 (EL).

Open Access This article is distributed under the terms of the Creative Commons Attribution 4.0 International License (http://crea tivecommons.org/licenses/by/4.0/), which permits unrestricted use, 
distribution, and reproduction in any medium, provided you give appropriate credit to the original author(s) and the source, provide a link to the Creative Commons license, and indicate if changes were made.

\section{References}

Ahlfors R, Lång S, Overmyer K, Jaspers P, Brosché M, Tauriainen A, Kollist H, Tuominen H, Belles-Boix E, Piippo M, Inzé D, Palva ET, Kangasjärvi J (2004) Arabidopsis RADICAL-INDUCED CELL DEATH1 belongs to the WWE protein-protein interaction domain protein family and modulates abscisic acid, ethylene, and methyl jasmonate responses. Plant Cell 16:1925-1937

Akhkha A, Reid I, Clarke DD, Dominy P (2001) Photosynthetic light response curves determined with the leaf oxygen electrode: minimisation of errors and significance of the convexity term. Planta 214:135-141

Baker NR, Rosenqvist E (2004) Applications of chlorophyll fluorescence can improve crop production strategies: an examination of future possibilities. J Exp Bot 55:1607-1621

Baranska M, Roman M, Dobrowolski JC, Schulz H, Baranski R (2013) Recent advances in Raman analysis of plants: alkaloids, carotenoids and polyacetylenes. Curr Anal Chem 9:108-127

Berger S (2002) Jasmonate-related mutants of Arabidopsis as tools for studying stress signaling. Planta 214:497-504

Berger S, Benediktyová Z, Matous K, Bonfig K, Mueller MJ, Nedbal L, Roitsch T (2007) Visualization of dynamics of plantpathogen interaction by novel combination of chlorophyll fluorescence imaging and statistical analysis: differential effects of virulent and avirulent strains of $P$. syringae and of oxylipins on A. thaliana. J Exp Bot 58:797-806

Bradford M (1976) A rapid and sensitive method for the quantitation of microgram quantities of protein utilizing the principle of protein-dye binding. Anal Biochem 72:248-254

Chandra A, Jain R, Solomon S (2012) Complexities of invertases controlling sucrose accumulation and retention in sugarcane. Curr Sci 102:857-866

Chang CC, Ball L, Fryer MJ, Baker NR, Karpinski S, Mullineaux PM (2004) Induction of ASCORBATE PEROXIDASE 2 expression in wounded Arabidopsis leaves does not involve known woundsignalling pathways but is associated with changes in photosynthesis. Plant J 38:499-511

Ciereszko I, Barbachowska A (2000) Sucrose metabolism in leaves and roots of bean (Phaseolus vulgaris L.) during phosphate deficiency. J Plant Physiol 156:640-644

Ciereszko I, Kleczkowski L (2005) Expression of several genes involved in sucrose/starch metabolism as affected by different strategies to induce phosphate deficiency in Arabidopsis. Acta Physiol Plant 27:147-155

Ciereszko I, Kleczkowski LA (2006) Phosphate deficiency-dependent upregulation of UDP-glucose pyrophosphorylase genes is insensitive to ABA and ethylene status in Arabidopsis leaves. Acta Physiol Plant 28:387-393

Couée I, Sulmon C, Gouesbet G, El Amrani A (2006) Involvement of soluble sugars in reactive oxygen species balance and responses to oxidative stress in plants. J Exp Bot 57:449-459

Delessert C, Wilson IW, Van Der Straeten D, Dennis S, Dolferus R (2004) Spatial and temporal analysis of the local response to wounding in Arabidopsis leaves. Plant Mol Biol 55:165-181

Devi R, Munjral N, Gupta AK, Kaur N (2007) Cadmium induced changes in carbohydrate status and enzymes of carbohydrate metabolism, glycolysis and pentose phosphate pathway in pea. Environ Exp Bot 61:167-174
Gabara B, Kuźniak E, Skłodowska M, Surówka E, Miszalski Z (2012) Ultrastructural and metabolic modifications at the plant-pathogen interface in Mesembryanthemum crystallinum leaves infected by Botrytis cinerea. Environ Exp Bot 77:33-43

Kim K, Portis AR (2005) Temperature dependence of photosynthesis in Arabidopsis plants with modifications in Rubisco activase and membrane fluidity. Plant Cell Physiol 46:522-530

Koo AJK, Howe GA (2009) The wound hormone jasmonate. Phytochemistry 70:1571-1580

Kunz S, Pesquet E, Kleczkowski LA (2014) Functional dissection of sugar signals affecting gene expression in Arabidopsis thaliana. PLoS One 9:e100312

Kunz S, Pesquet E, Kleczkowski LA (2015) Hexokinase 1 is required for glucose-induced repression of bZIP63, At5g22920 and BT2 in Arabidopsis. Front Plant Sci 6:525

Lafta AM, Fugate KK (2011) Metabolic profile of wound-induced changes in primary carbon metabolism in sugarbeet root. Phytochemistry 72:476-489

Lastdrager J, Hanson J, Smeekens S (2014) Sugar signals and the control of plant growth and development. J Exp Bot 65:799-807

León P, Sheen J (2003) Sugar and hormone connections. Trends Plant Sci 8:110-116

León J, Rojo E, Sánchez-Serrano JJ (2001) Wound signalling in plants. J Exp Bot 52:1-9

Ljung K, Nemhauser JL, Perata P (2015) New mechanistic links between sugar and hormone signalling networks. Cur Opin Plant Biol 25:130-137

Łukaszuk E, Ciereszko I (2012) Plant responses to wounding stress. In: Łaska G (ed) Biological diversity-from cell to ecosystem. Polish Botanical Society, Białystok, pp 73-85

Lulai EC, Suttle JC, Olson LL, Neubauer JD, Campbell LG, Campbell MA (2016) Wounding induces changes in cytokinin and auxin content in potato tuber, but does not induce formation of gibberellins. J Plant Physiol 191:22-28

Machado RAR, Arce CCM, Ferrieri AP, Baldwin IT, Erb M (2015) Jasmonate-dependent depletion of soluble sugars compromises plant resistance to Manduca sexta. New Phytol 207:91-105

Maffei ME, Mithöfer A, Boland W (2007) Before gene expression: early events in plant-insect interaction. Trends Plant Sci 12:310-316

Meyerowitz EM (2001) Prehistory and history of Arabidopsis research. Plant Physiol 125:15-19

Nelson NJ (1944) A photometric adaptation of the Somogyi method for the determination of glucose. J Biol Chem 153:375-380

Overmyer K, Tuominen H, Kettunen R, Betz C, Langebartels C, Sandermann H, Kangasjärvi J (2000) Ozone-sensitive Arabidopsis rcdl mutant reveals opposite roles for ethylene and jasmonate signaling pathways in regulating superoxide-dependent cell death. Plant Cell 12:1849-1862

Park J, Halitschke R, Kim HB, Baldwin IT, Feldmann KA (2002) A knock-out mutation in allene oxide synthase results in male sterility and defective wound signal transduction in Arabidopsis due to a block in jasmonic acid biosynthesis. Plant J 31:1-12

Polit JT, Ciereszko I (2012) Sucrose synthase activity and carbohydrates content in relation to phosphorylation status of Vicia faba root meristems during reactivation from sugar depletion. J Plant Physiol 169:1597-1606

Quilliam RS, Swarbrick PJ, Scholes JD, Rolfe SA (2006) Imaging photosynthesis in wounded leaves of Arabidopsis thaliana. J Exp Bot 57:55-69

Reymond P, Weber H, Damond M, Farmer EE (2000) Differential gene expression in response to mechanical wounding and insect feeding in Arabidopsis. Plant Cell 12:707-720

Ritchie GA (2006) Chlorophyll fluorescence: what is it and what do the numbers mean? USDA For Serv Proc 43:34-43

Roman G, Lubarsky B, Kieber JJ, Rothenberg M, Ecker R (1995) Genetic analysis of ethylene signal transduction in Arabidopsis 
thaliana: five novel mutant loci integrated into a stress response pathway. Genetics 139:1393-1409

Rosa M, Prado C, Podazza G, Interdonato R, González JA, Hilal M, Prado FE (2009) Soluble sugars metabolism, sensing and abiotic stress: a complex network in the life of plants. Plant Signal Behav 4:388-393

Rosenkranz H, Vogel R, Greiner S, Rausch T (2001) In wounded sugar beet (Beta vulgaris L.) tap-root, hexose accumulation correlates with the induction of a vacuolar invertase isoform. J Exp Bot 52:2381-2385

Ruan Y-L, Jin Y, Yang Y-J, Li G-J, Boyer JS (2010) Sugar input, metabolism, and signaling mediated by invertase: roles in development, yield potential, and response to drought and heat. Mol Plant 3:942-955

Savatin DV, Gramegna G, Modesti V, Cervone F (2014) Wounding in the plant tissue: the defense of a dangerous passage. Front Plant Sci 5:1-11

Schulz H, Baranska H, Baranski R (2005) Potential of NIR-FTRaman spectroscopy in natural carotenoid analysis. Biopolymers 77:212-221

Skoczowski A, Troć M (2013) Isothermal calorimetry and Raman spectroscopy to study response of plants to abiotic and biotic stresses. In: Rout GR, Das AB (eds) Molecular stress physiology of plants. Springer, Berlin, pp 263-288
Strand Å, Hurry V, Gustafsson P (1997) Development of Arabidopsis thaliana leaves at low temperatures releases the suppression of photosynthesis and photosynthetic gene expression despite the accumulation of soluble carbohydrates. Plant J 12:605-614

Szechyńska-Hebda M, Kruk J, Górecka M, Karpińska B, Karpiński S (2010) Evidence for light wavelength-specific photoelectrophysiological signaling and memory of excess light episodes in Arabidopsis. Plant Cell 22:2201-2218

Tauzin AS, Giardina T (2014) Sucrose and invertase, a part of the plant defense response to the biotic stresses. Front Plant Sci $5: 293$

Verma AK, Upadhyay SK, Srivastava MK, Verma PC, Solomon S, Singh SB (2011) Transcript expression and soluble acid invertase activity during sucrose accumulation in sugarcane. Acta Physiol Plant 33:1749-1757

Wellburn AR (1994) The spectral determination of chlorophyll a and $\mathrm{b}$, as well as total carotenoids, using various solvents with spectrophotometers of different resolution. Plant Physiol 144:307-313

Withnall R, Chowdhry BZ, Silver J, Edwards HGM, de Oliveira LFC (2003) Raman spectra of carotenoids in natural products. Spectrochim Acta Part A Mol Bio Spectr 59:2207-2212 